\title{
O COMPROMETIMENTO ORGANIZACIONAL COMO DETERMINANTE DA VOZ - UM ESTUDO DE PERFIS
}

\author{
Ana Nascimento Sabino ${ }^{1}$ \\ Albino Lopes ${ }^{2}$
}

\begin{abstract}
RESUMO: Testou-se um modelo que relaciona as três componentes do comprometimento organizacional com a voz, mediada pela satisfação com o trabalho. Introduziram-se dois perfis baseados na componente normativa. Um primeiro, denominados de Dever Moral de elevada componente afetiva e normativa e um segundo com elevada componente calculativa e normativa denominado de Obrigação por Dívida (Meyer \& Parfyonova, 2010).

Foi testado, inicialmente, o modelo proposto. Posteriormente verificou-se em que medida é que esse modelo diferia de um perfil de Dever Moral para um perfil de Obrigação por Dívida.

Os resultados revelaram que cada um dos perfis determinava modelos diferentes, pelo que demostrou-se a necessidade de se continuar a realizar estudos referentes à componente normativa. Este trabalho revelou também a importância em percecionar os diferentes tipos de vozes que emergem nestes contextos. Finalmente, invoca-se a necessidade das organizações passarem a gerir os afetos, visto a componente afetiva ter assumido um papel preponderante independentemente do perfil de comprometimento.

Foram discutidas as implicações dos resultados obtidos.
\end{abstract}

Palavras-chave: Comprometimento Organizacional, Perfis de Comprometimento, Voz, Satisfação com o Trabalho.

ABSTRACT: A model that combines the three components of Organizational Commitment and Voice was tested and mediated by job satisfaction. Two commitment profile were set. The first, "Moral Duty", is based on affective and normative components association, and the second, "Indebted Obligation", formed by normative and continuance association (Meyer \& Parfyonova, 2010)

\footnotetext{
${ }^{1}$ Mestre em Gestão dos Recursos Humanos pelo ISCTE-IUL, tendo sido orientada pelo segundo autor.

${ }^{2}$ Professor Catedrático do ISCSP-UTL
} 
The proposed model was tested in an initial stage. Later it was tested if that model differed from a "Moral Duty profile" or from an "Indebted Obligation profile".

Results have shown the need of continuing Normative Component studies. This thesis also suggests the importance of studying different "Voice" types that emerge from different organizational contexts. At last, results show that there is a growing need of Affects Management within organizations once that Affective Component plays a critical role regardless of Commitment profile.

The implications of the findings were discussed.

Key-Words: Organizational Commitment, Commitment Profiles, Voice, Job Satisfaction.

\section{INTRODUÇÃO}

Atualmente tem-se vindo a assistir a uma conjuntura socioeconómica e organizacional marcada pela imprevisibilidade, onde os processos de gestão em geral, e dos recursos humanos em particular, assumem um papel fundamental para o sucesso das organizações (Drucker, 1986; Meyer, 2009; Meyer, Allen \& Topulnytsky, 1998).

Meyer e Hersovitch (2001) identificam constructos, como o comprometimento, que atuam como elementos potenciadores de processos organizacionais e que vão permitir às organizações criarem um sentido de pertença nos seus colaboradores (Weick, 1995), independentemente da conjuntura. Importa assim conciliar estes dois fatores (mudança do contexto e comprometimento) de forma a tornar as organizações mais competitivas. Esta questão é central na medida em que a "...mudança organizacional tem o potencial de minar o comprometimento do empregado, mas o comprometimento é essencial para o sucesso da implementação da mudança" (Meyer, 2009: 38).

No seguimento das questões acima levantadas, Nascimento (2010) desenvolveu um estudo relativo à influência do comprometimento organizacional nas estratégias comportamentais, tendo como variáveis mediadoras dessa relação o comprometimento com os objetivos e a satisfação global com o trabalho. Os resultados obtidos pelo autor sugerem a necessidade de aprofundar esta temática, nomeadamente no que diz respeito a duas questões. Uma referente ao papel e à natureza da voz, já que o autor conclui que "Os resultados destacaram um papel de charneira desempenhado pela voz" (Nascimento, 2010: 282). A outra advém do fato de "... as três componentes do comprometimento organizacional estavam relacionadas positivamente entre si" (Nascimento, 2010: 279), sugerindo então que “... a utilização de perfis de comprometimento permite uma melhor compreensão quer dos 
determinantes de cada um desses perfis, quer também das suas consequências" (Nascimento, 2010: 280).

Propõem-se então, dar continuidade ao trabalho de Nascimento (2010) introduzindo a noção dos perfis do comprometimento organizacional. De fato, tendo em conta a conjuntura atual, tem-se vindo a assistir a um aumento de estudos sobre a relação entre as diferentes componentes do comprometimento organizacional, ao invés do estudo de cada componente separadamente, como vinha sendo habitual.

Pretende-se assim responder à seguinte questão: Em que medida é que a relação entre o comprometimento organizacional e a voz, mediada pela satisfação com o trabalho é influenciada pelos perfis de comprometimento baseados na componente normativa? Identificaram-se assim, três objetivos específicos. O primeiro visa estudar em que medida é que as três componentes do comprometimento organizacional determinam a voz. Seguidamente, importa analisar a satisfação com o trabalho enquanto mediadora desta relação. Finalmente, com introdução dos perfis de comprometimento, pretende-se aferir em que medida é que as relações entre as componentes do comprometimento organizacional e a voz são influenciadas, por um lado pelo perfil Dever Moral e por outro pelo perfil Obrigação por Dívida.

Para tal, teoricamente, adotou-se a abordagem de Meyer e Allen (1991) para a definição das três componentes do comprometimento. Já os perfis de comprometimento foram definidos segundo Meyer e Parfyonova (2010). A voz é vista segundo a perspetiva de Farrell e Rusbult (1982) no Modelo EVLN e a satisfação com o trabalho na ótica do Modelo das Características da Função de Hackman e Oldham (1980).

\section{REVISÃO DE LITERATURA}

\section{Comprometimento Organizacional}

Adotou-se a perspetiva do comprometimento organizacional de Meyer e Allen (1991: 67) que, no Modelo das Três Componentes do Comprometimento Organizacional, sistematizaram que este constructo "... (a) caracteriza a relação do empregado com a organização, $e$ (b) tem implicações na decisão de continuar membro da organização" (Meyer \& Allen, 1991: 67). O comprometimento deve assim ser entendido como um estado psicológico entre o indivíduo e a organização que determina se o sujeito deseja ou não, manter-se nessa organização. É, segundo os autores, um constructo multidimensional, sendo composto por três componentes afetiva, calculativa e normativa. A componente afetiva do comprometimento organizacional refere-se a uma ligação emocional / afetiva entre o indivíduo e a organização. Neste caso, o sujeito irá 
permanecer na organização por vontade própria. Já a componente calculativa diz respeito aos aspetos materiais e extrínsecos que se apresentam na relação entre o indivíduo e a organização onde atua. Tratase da dimensão onde a decisão em manter-se na organização se deve a necessidades de ordem material, ou seja, à avaliação dos custos inerentes a uma mudança de organização. Finalmente, a componente normativa prende-se com o sentimento de responsabilidade / dívida que o sujeito tem com a organização sendo que o indivíduo apenas permanece porque tem um dever para com a organização.

A estes três estados psicológicos que caracterizam o comprometimento organizacional e são considerados as suas componentes, Meyer e Allen (1991) denominaram o "Modelo das TrêsComponentes do Comprometimento Organizacional". Os autores propõem assim um modelo integrado que perspetiva os antecedentes distantes, os antecedentes próximos, os processos e as consequências das três componentes do comprometimento ao nível dos comportamentos do indivíduo.

\section{Perfis de Comprometimento Organizacional}

As componentes do comprometimento organizacional não são mutuamente exclusivas, sendo que o sujeito pode experienciar diferentes tipos de comprometimentos e com diferentes intensidades. Recentemente, tem-se vindo a verificar uma preocupação em analisar as relações entre as diferentes componentes do comprometimento, ao invés do estudo de cada componente separadamente como vinha sendo habitual, visto os mesmos considerarem que esta análise é mais limitativa (Meyer \& Herscovitch, 2002; Gellaty, Meer \& Luchak, 2006; Wasti, 2005; Meyer \& Parfyonova, 2010).

É nesta linha que surgem os trabalhos relativos aos Perfis de Comprometimento, que, segundo a abordagem de Meyer e Parfyonova (2010) podem ser entendidos como a forma como as três componentes do comprometimento de Meyer e Allen (1991) se relacionam e com que intensidades. Neste sentido, os autores defendem a reconceptualização da componente normativa na medida em que, até à data, esta componente tem sido pouco estudada, sendo alvo de críticas, tendo-se questionado a pertinência em mantê-la quando as correlações com a componente afetiva são elevadas.

Meyer e Parfyonova (2010) propõem a criação de dois perfis de comprometimento que refletem a dualidade da componente normativa. $\mathrm{O}$ primeiro perfil denominado de Dever Moral é composto pela associação da componente normativa (enquanto valor) e a afetiva. Este perfil caracteriza-se por um elevado desejo em tomar ações em benefício de 
determinado alvo porque moralmente é o que se deve fazer. O segundo perfil, que os autores denominam de Obrigação por Dívida, composto pela associação da componente normativa (enquanto obrigação) e calculativa, é entendido como a realização de ações em benefício de determinado alvo a evitar ou minimizar custos.

\section{Satisfação com o Trabalho}

A satisfação com o trabalho pode ser entendida como “... uma reação afetiva a estados psicológicos determinados por características organizacionais e funcionais." (Nascimento, Lopes, \& Salgueiro, 2008: 87) sendo vista como um constructo mutável e dinâmico. Neste âmbito, adotou-se o Modelo das Características da Função de Hackman e Oldham (1980) que postula que a satisfação pode ser explicada por fatores situacionais, nomeadamente as características da função. Note-se que este modelo distingue a satisfação global da satisfação com as várias facetas do trabalho. Neste sentido, a satisfação com o trabalho, segundo Hackman e Oldham (1980) é um constructo unidimensional, devendo ser entendida como um resultado global que resulta da integração dos diferentes fatores, sejam eles intrínsecos ou extrínsecos.

Voz

O estudo das estratégias comportamentais segue a perspetiva de Farrell e Rusbult (1983) no Modelo EVLN. Esta teoria tem como base o trabalho de Hirschman (1970), que visa explicitar de que forma os utilizadores reagiam ao decréscimo da satisfação geral de diferentes entidades. Farrell e Rusbult (1983) procuram compreender as estratégias comportamentais que os colaboradores optam perante uma situação de insatisfação no trabalho. Foram então identificadas quatro estratégias: a saída, a voz, a lealdade e a negligência. Neste âmbito, urge clarificar a voz, estratégia ativa e construtiva que consiste em comportamentos prósociais orientados para o sucesso da organização e para a eficácia e eficiência do desempenho dos atores organizacionais. É pois " a única forma pela qual clientes ou empregados insatisfeitos podem reagir sempre que a opção de saída não é viável" (Hirschman, 1970: 33). A relação inversa assiste-se na medida em que a voz tem tendência a aumentar à medida que as oportunidades de saída diminuem.

De notar que este modelo, na sua globalidade, e cada uma das estratégias, em particular, à exceção da saída, não tem sido alvo de muitos estudos. De fato, no que concerne à relação entre o comprometimento organizacional e as estratégias comportamentais sob o ponto de vista do modelo EVLN, apenas se identificou o estudo de Nascimento (2010). 


\section{Hipóteses}

Tendo em consideração a abordagem teórica adotada, bem como as conclusões de estudos anteriores (Nascimento, 2010), foram definidos seis grupos de hipóteses gerais, as quais podem, ainda, ser melhor compreendidas através de sub - hipóteses. O primeiro grupo de hipóteses (H1) refere-se à relação de antecedência entre as três componentes do comprometimento organizacional e a voz. Os resultados do estudo de Nascimento (2010: 244) servem de base às hipóteses formuladas, verificando-se uma relação de antecedência positiva da componente afetiva sobre a voz. $\mathrm{O}$ autor determina também, que não parece haver uma relação entre a componente normativa e a voz e, para além desse fato, que a relação de antecedência que se estabelece entre a componente calculativa e a voz seria, igualmente, negativa. Em seguida, apresentamse as hipóteses (H2) que dizem respeito à antecedência das componentes do comprometimento organizacional em relação à satisfação com o trabalho. Os resultados de Nascimento (2010: 243) apontam, igualmente, que “... a satisfação com o trabalho (...) seja um constructo integrador de diferentes facetas do indivíduo (...) nomeadamente das diferentes naturezas do comprometimento (...)". Neste sentido, as hipóteses formuladas neste trabalho relativas a esta temática, vão ao encontro destas conclusões na medida em que as três componentes do comprometimento (afetiva, normativa e calculativa) são tidas como variáveis antecedentes da satisfação. A terceira hipótese (H3) prende-se com a relação entre a satisfação e a voz. De notar que o quadro teórico referente ao Modelo EVLN postula que “... a satisfação com o trabalho apresente uma relação causal positiva com estratégias comportamentais construtivas e negativa com estratégias comportamentais destrutivas" (Nascimento, 2010: 136). Esta hipótese também já foi confirmada no estudo de Nascimento (2010) tendo sido originalmente testada por vários autores entre os quais Brief e Weiss (2002) e Bowling (2007). O quarto grupo de hipóteses (H4) refere-se ao papel da satisfação, enquanto variável mediadora da relação de antecedência das componentes do comprometimento com a voz. Tendo, efetivamente, em conta os resultados obtidos por Nascimento (2010: 242) verifica-se que as três componentes do comprometimento são variáveis antecedentes positivas da satisfação. Adicionalmente, refira-se que Vandenberg e Lance (1992) realizaram um estudo longitudinal, durante 5 meses, que pretendia aferir a evolução da relação causal entre a satisfação e o comprometimento organizacional, e os resultados apontaram para $\mathrm{o}$ fato de comprometimento dever ser visto como antecedente causal da satisfação.

Importa, enfim, identificar o nível de influência dos perfis do comprometimento no modelo proposto (H5). De fato, os trabalhos 
desenvolvidos nesta área referem que os comportamentos dos colaboradores no local de trabalho podem ser melhor explicados pelos perfis do que pelos diferentes comprometimentos, em separado (Wasti, 2005; Gellatly et al., 2006; Meyer \& Parfyonova: 2010). Adicionalmente, Nascimento (2010: 295) também sugeriu que "A utilização de perfis iria permitir uma melhor compreensão da influência de cada perfil no sistema de relações estruturais estabelecidas no modelo". Para além de verificar se, de fato, os perfis influenciam o modelo, importa também caracterizar de que forma é que se estabelece essa influência e em que tipo de relações é que se verifica uma maior influência desses mesmos perfis (H6). Assim, o sexto conjunto de hipóteses procura enfatizar a especificidade da influência dos dois perfis em estudo em cada relação estabelecida no modelo proposto.

Neste sentido, tendo em conta que "nós argumentamos que a componente normativa tem uma dupla natureza e que se manifesta de forma diferente consoante a força da outra componente que lhe está associada" (Meyer \& Parfyonova, 2010: 283), postula-se neste âmbito que cada perfil tenha maior influência nas relações que se estabelecem entre as componentes que o compõem, a voz ou a satisfação. A componente normativa é uma exceção, na medida em que é comum aos dois perfis. Neste sentido, é expectável que o comprometimento normativo não seja determinante na influência dos perfis no modelo proposto. Assim, a influência dá-se pela componente afetiva e calculativa, ou seja, pelas componentes específicas de cada perfil e não pela componente comum. Finalmente, a última hipótese refere-se à relação entre a satisfação e a voz. Neste caso não se verifica qualquer alteração consoante os perfis, visto a relação não contemplar qualquer variável de composição do perfil.

\section{METODOLOGIA}

Adotou-se uma metodologia quantitativa, tendo sido utilizado o inquérito por questionário. Foram distribuídos 912 questionários, e a taxa de adesão foi de $40 \%$. Após eliminação de 16 questionários por não terem variabilidade de respostas, a amostra final, por conveniência, foi constituída por 345 participantes que trabalhavam em empresas do ramo industrial.

Partiu-se das escalas já anteriormente utilizadas por Nascimento $(2010)^{3}$ na medida em que o presente estudo se propõe replicar parte do

\footnotetext{
${ }^{3}$ Para o Modelo das Três Componentes de Meyer e Allen (1991) utilizaram-se os itens propostos pelos autores para cada componente. No caso da satisfação a escala utilizada está incluída no Questionário de Diagnóstico de Função (JDS) de Hackman e
} 
modelo proposto pelo autor. Note-se que todas as escalas revelaram boas propriedades psicométricas. Ao nível da caracterização da amostra introduziram-se variáveis sociodemográficas e de caracterização funcional.

Relativamente às escalas de resposta do comprometimento organizacional e da satisfação com o trabalho, ambas são de Likert de 7 pontos, na qual (1) corresponde a "Discordo Totalmente" e (7) "Concordo Totalmente", ao passo que, no caso da voz, optou-se por uma escala de resposta de tipo Likert de cinco posições em que (1) correspondia a "Discordo em Absoluto" e (5) a "Concordo em Absoluto".

\section{Caracterização da Amostra}

A amostra obtida caracterizou-se fundamentalmente pela sua forte componente industrial, tendo sido constituída por $62 \%$ de homens e $37,9 \%$ de mulheres. Em média os participantes tinham 38 anos e 10 de antiguidade, este último com um desvio-padrão de 8 anos. Os resultados sugerem também, a existência de maior afluência de respostas por parte de participantes que se caracterizaram por trabalharem em áreas técnicas e serem quadros médios.

\section{RESULTADOS}

Numa primeira fase, de cariz exploratório e cujos resultados não serão apresentados neste contexto, efetuou-se a validação das escalas face à amostra, através de uma Análise Fatorial Exploratória ${ }^{4}$ (AFE), seguida de uma Análise Fatorial Confirmatória (AFC) para cada uma das escalas de medida dos constructos em causa: o comprometimento organizacional, a satisfação com o trabalho e a voz. Os resultados obtidos implicaram a eliminação de itens, de forma a conseguir que os modelos finais tivessem uma melhor bondade de ajustamento ${ }^{5}$.

\section{Análise descritiva das variáveis latentes}

$\mathrm{Na}$ segunda fase, com base nos resultados fatoriais, procedeu-se à construção de índices ponderados para os três constructos em análise.

Oldham (1980). Já a escada da voz, Nascimento (2010) sistematizou um conjunto de estudos onde diversos autores propõem escalas para cada uma das estratégias comportamentais, elaborando assim uma escala original.

${ }^{4}$ Para a AFE utilizou-se o método de estimação por máxima verosimilhança (Maximum Likelihood) tendo-se também optado por utilizar o método de rotação oblíqua Promax, (Maroco, 2007; Rummell, 2002).

${ }^{5}$ Foi considerado dispensável colocar os itens que foram eliminados para cada constructo. 
Utilizou-se, para isso, como fator de ponderação, os "fator loadings" dos itens que constam no modelo final.

Os resultados sugerem que a amostra utilizada apresenta níveis inferiores ao ponto central da escala, no respeitante aos constructos em análise $^{6}$ (Tabela 1), sendo os desvios-padrão de aproximadamente um ponto. Assim, numa primeira análise, é possível concluir que, na globalidade, os participantes têm baixos níveis de comprometimento. Por outro lado, os participantes têm um sentimento neutro em relação à satisfação e não praticam o exercício da voz nos seus contextos profissionais.

Ainda assim, numa análise mais detalhada, importa salientar que, apesar de serem valores baixos, a ligação dos participantes à organização é mais de carácter afetivo $(\mathrm{M}=4,37 ; \mathrm{DP}=1,07)$. Contrariamente, a ligação instrumental (calculativa) bem como a normativa são mais baixas (respetivamente $\mathrm{M}=3,03 ; \mathrm{DP}=1,12$ e $\mathrm{M}=3,13 ; \mathrm{DP}=1,21$ ).

\section{Tabela 1}

Média, Desvios-Padrão e Matriz de Correlações dos constructos em análise (Índices Ponderados pelo factor loading)

\begin{tabular}{cccccccc}
\hline & Média & Desvio-Padrão & CAf & CN & CC & Sat & V \\
\hline CAf & 4,37 & 1,07 & 1,00 & & & & \\
\hline CN & 3,13 & 1,21 & 0,37 & 1 & & & \\
\hline CC & 3,03 & 1,12 & 0,07 & 0,44 & 1 & & \\
\hline Sat & 4,35 & 1,11 & 0,40 & 0,49 & 0,33 & 1 & \\
\hline V & 2,97 & 0,70 & 0,44 & 0,26 & $-0,03$ & 0,29 & 1 \\
\hline
\end{tabular}

Estes resultados, nomeadamente os valores relativos à componente normativa e calculativa, poderão estar associados à conjuntura atual portuguesa, nomeadamente no setor em questão. Emocionalmente, os indivíduos continuam ligados à organização, mas tanto o sentido de responsabilidade como o de custos associados à mudança têm tendência $\mathrm{a}$ ser inferiores ao afetivo devido ao conjunto de medidas que têm vindo a ser tomadas no contexto da crise, nomeadamente, face à incerteza de uma possível mudança e / ou ausência / diminuição de alternativas credíveis.

Relativamente às correlações entre os diferentes constructos, denotese que não se verificam correlações altas. No entanto, sugere-se uma associação entre a componente afetiva e a normativa $(0,37)$ e entre a normativa e a calculativa $(0,44)$, conforme é estabelecido no quadro teórico. Destaca-se também, a relação positiva entre a componente afetiva

\footnotetext{
${ }^{6}$ Relembre-se que tanto para o comprometimento organizacional como para a satisfação utilizou-se uma escala tipo Likert de sete pontos, ao passo que para a voz utilizou-se uma escala tipo Likert de cinco pontos.
} 
e a voz $(0,44)$ e a ausência de relação entre a componente calculativa e a voz $(-0,03)$. Já a satisfação apresenta-se relacionada com as três componentes $(0,40 ; 0,49 ; 0,33$, respetivamente). Os resultados sugerem também que não existe associação entre a componente afetiva e a calculativa $(0,07)$, o que está em linha com o quadro teórico estabelecido (Meyer \& Paryfonova, 2010).

\section{Estimação do Modelo e Teste das Hipóteses}

A terceira fase diz respeito à estimação do modelo e teste das hipóteses. Procedeu-se inicialmente à estimação do modelo proposto utilizando-se para isso a metodologia de modelagem por equações estruturais ("Strutured Equation Modeling" - SEM). Estando estabelecido o modelo estrutural, as relações de mediação foram testadas através do valor de z' (Mackinnon, Lockwood, Hoffman, West \& Sheets, $2002)^{7}$, Por fim, determinou-se a influência de cada perfil - dever moral e obrigação por dívida - no modelo proposto, através da análise multigrupos. À medida que forem apresentados os resultados obtidos, serão discutidas e testadas as hipóteses em estudo.

Depois da validação das variáveis manifestas compósitas de cada constructo, passou-se ao estudo do modelo proposto. Apresenta-se de seguida o modelo final que apresenta uma boa bondade de ajustamento (Tabela 2).

\section{Tabela 2}

Medidas de Bondade de Ajustamento do Modelo Final

\begin{tabular}{lcc}
\hline Indicadores & Critérios de Aceitabilidade & Modelo Final \\
\hline \multicolumn{3}{c}{ Medidas de Ajustamento Absoluto } \\
\hline RMSEA & Desejável $\leq 0,08$ & 0,047 \\
\hline GFI & Desejável $\geq 0,90$ & 0,86 \\
\hline$x^{2}$ & p-value $\leq 0,05$ & 219,45 \\
\hline \multicolumn{3}{c}{ Medidas de Ajustamento Incremental } \\
\hline CFI & Desejável $\geq 0,90$ & 0,98 \\
\hline \multicolumn{3}{c}{ Medidas de Parcimónia e de Comparação de Modelos } \\
\hline$x^{2} /$ df & Desejável $\leq 3$ & 1,55 \\
\hline Modelo AIC & Modelo com o menor valor AIC & 315,45 \\
\hline
\end{tabular}

No modelo final (Figura 1) verifica-se que a voz é determinada positivamente pela componente afetiva do comprometimento e, negativamente, pela componente calculativa. Verifica-se também uma relação não significativa entre a componente normativa e esta estratégia comportamental. No entanto, realce-se que a relação entre estes constructos é mais significativa na componente afetiva que na

\footnotetext{
${ }^{7}$ Este estabelece a significância dos efeitos indiretos das relações de mediação para valores de z' superiores a 0,97 a um nível de significância de 0,05 .
} 
componente calculativa. Nota-se também que a satisfação é determinada, positivamente, pelas três componentes do comprometimento organizacional. Por fim, destaque-se que a voz também é determinada, positivamente, pela satisfação.

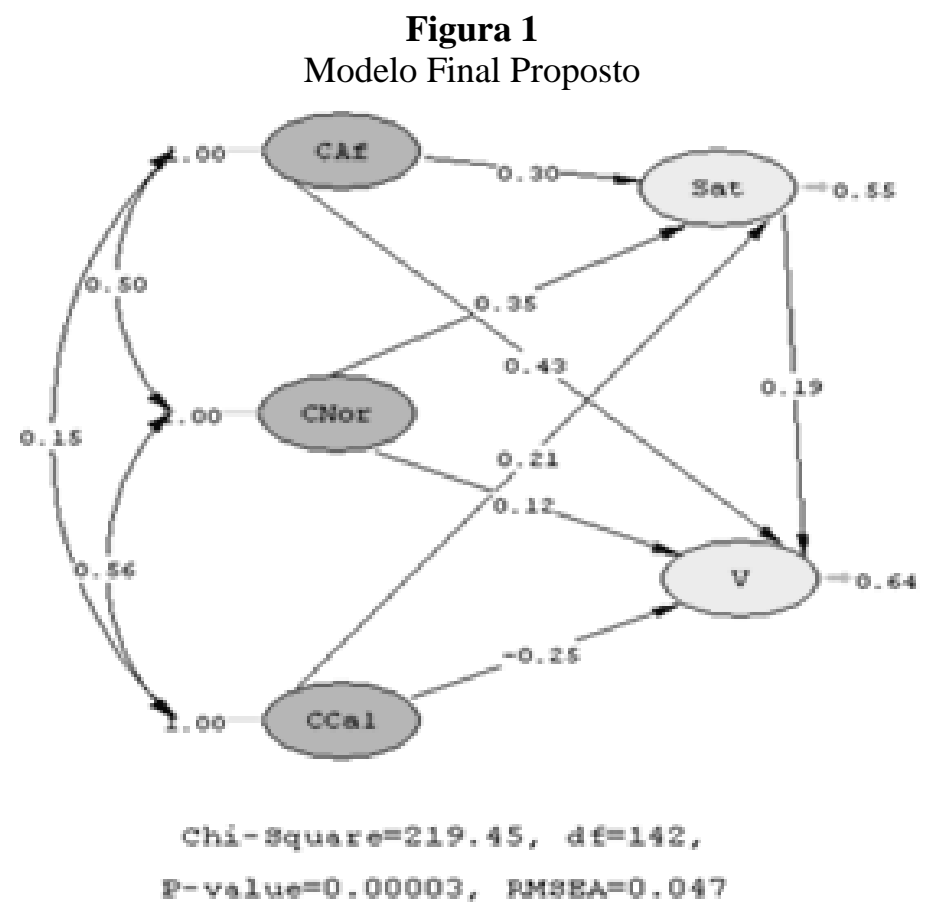

Está-se então em condições de validar as hipóteses em estudo relativas à validação do modelo proposto $(\mathrm{H} 1, \mathrm{H} 2 \mathrm{e} \mathrm{H} 3)$.

No respeitante à relação entre as componentes do comprometimento organizacional e a voz $(\mathrm{H} 1)$, os resultados sugerem a não rejeição das três hipóteses. Assim, os resultados apontam para que a componente afetiva seja determinante positiva da voz, ao passo que a calculativa é uma determinante negativa da voz. Verifica-se também que a componente normativa não está diretamente relacionada com esta estratégia comportamental (Tabela 3).

Relativamente à relação entre as componentes do comprometimento com a satisfação (H2), os resultados sugerem que todas as componentes determinam positivamente a satisfação, realçando-se então o seu carácter integrativo, fato este também verificado no estudo de Nascimento (2010). No caso do comprometimento calculativo, verifica-se uma alteração de 
sentido na medida em que esta componente determina negativamente a voz e positivamente a satisfação (Tabela 4).

Tabela 3

Teste das hipóteses H1

\begin{tabular}{llll}
\hline Hipóteses & Estimativa & Conclusão \\
\hline H1.1 & $\begin{array}{l}\text { A componente afetiva é uma variável antecedente positiva da } \\
\text { voz }\end{array}$ & $0,43(3,81)$ & $\begin{array}{l}\text { Não } \\
\text { Rejeitada }\end{array}$ \\
\hline H1.2 & $\begin{array}{l}\text { A componente normativa não está diretamente relacionada com a } \\
\text { voz }\end{array}$ & $0,12(0,99)$ & $\begin{array}{l}\text { Não } \\
\text { Rejeitada }\end{array}$ \\
\hline H1.3 & $\begin{array}{l}\text { A componente calculativa é uma variável antecedente negativa } \\
\text { da voz }\end{array}$ & $-0,25(-2,71)$ & $\begin{array}{l}\text { Não } \\
\text { Rejeitada }\end{array}$ \\
\hline
\end{tabular}

Apresenta-se entre parêntesis o valor do T-Value

A segunda conclusão a salientar prende-se com o fato de, nesta relação, o comprometimento normativo assumir mais relevância que as restantes componentes. Relembre-se que esta componente não se relaciona diretamente com a voz.

Tabela 4

Teste das hipóteses H2

\begin{tabular}{llll}
\hline \multicolumn{1}{c}{ Hipóteses } & Estimativa & Conclusão \\
\hline $\mathrm{H} 2.1$ & $\begin{array}{l}\text { A componente afetiva é uma variável antecedente positiva da } \\
\text { satisfação }\end{array}$ & $0,30(2,83)$ & $\begin{array}{l}\text { Não } \\
\text { Rejeitada }\end{array}$ \\
\hline $\mathrm{H} 2.2$ & $\begin{array}{l}\text { A componente normativa é uma variável antecedente positiva da } \\
\text { satisfação }\end{array}$ & $0,35(3,15)$ & $\begin{array}{l}\text { Não } \\
\text { Rejeitada }\end{array}$ \\
\hline $\mathrm{H} 2.3$ & $\begin{array}{l}\text { A componente calculativa é uma variável antecedente positiva da } \\
\text { satisfação }\end{array}$ & $0,21(0,99)$ & $\begin{array}{l}\text { Não } \\
\text { rejeitada }\end{array}$ \\
\hline
\end{tabular}

Apresenta-se entre parêntesis o valor do T-Value

No que concerne à satisfação e à voz, verifica-se uma relação fraca ainda que significativa. É possível também validar a hipótese $\mathrm{H} 3$, na medida em que esta visa percecionar a antecedência da satisfação na voz (Tabela 5).

\section{Tabela 5}

Teste das hipóteses H3

\begin{tabular}{|c|c|c|c|}
\hline & Hipótese & Estimativa & Conclusão \\
\hline H3 & A satisfação é uma variável antecedente da voz & $0,19(1,98)$ & Não Rejeitada \\
\hline
\end{tabular}




\section{Análise das relações de mediação}

A análise de relações de mediação ${ }^{8}$ tem assumido maior importância na compreensão dos fenómenos sociais e psicológicos. Na realidade, esta técnica permite uma melhor compreensão das relações entre duas variáveis através de um, ou mais, mediadores. Estes são entendidos como variáveis que explicam uma sequência causal de outras duas variáveis (MacKinnon, Fairchild \& Fritz, 2007).

Verifica-se uma relação de mediação parcial entre cada componente do comprometimento e a voz (Tabela 6).

Apesar destes resultados, importa salientar o fato de a relação entre a componente normativa e a voz visto não ser significativa. Assim, dado que não se rejeitou a hipóteses 4.2 , que estabelece a satisfação com o trabalho como mediadora da relação de antecedência do comprometimento normativo com a voz, optou-se por testar também uma mediação total. Verificou-se um $Z^{\prime}=2,22$, que sustenta uma mediação total da satisfação na relação entre esta componente do comprometimento e a voz.

Conclui-se assim (Tabela 6) que os resultados sugerem a satisfação como sendo uma variável mediadora da relação de antecedência do comprometimento organizacional e a voz.

\section{Tabela 6}

Teste das hipóteses H4

\begin{tabular}{lllll}
\hline \multicolumn{7}{c}{ Hipótese } & Valor de $\mathrm{z}^{\prime}$ & Conclusão \\
\hline 4.1 & $\mathrm{H}$ & $\begin{array}{l}\text { A satisfação é uma variável mediadora da } \\
\text { relação de antecedência do } \\
\text { comprometimento afetivo sob a voz. }\end{array}$ & $\mathrm{z}^{\prime}=1,34$ & Não Rejeitada \\
\hline 4.2 & $\mathrm{H}$ & $\begin{array}{l}\text { A satisfação é uma variável mediadora da } \\
\text { relação de antecedência do } \\
\text { comprometimento normativo sob a voz. }\end{array}$ & $\mathrm{Z}^{\prime}=1,35$ & Não Rejeitada \\
\hline 4.3 & $\mathrm{H}$ & $\begin{array}{l}\text { A satisfação é uma variável mediadora da } \\
\text { relação de antecedência do } \\
\text { comprometimento calculativo sob a voz. }\end{array}$ & $\mathrm{z}^{\prime}=79,8$ & Não Rejeitada \\
\hline
\end{tabular}

\section{Análise Multigrupos por Perfis}

De forma a estudar a influência dos dois perfis - dever moral e obrigação por dívida - no modelo proposto, foi realizada uma análise

\footnotetext{
${ }^{8}$ Optou-se por utilizar a abordagem de Baron e Kenny (1986), também utilizada por Nascimento (2010). Utilizou-se o valor de z' proposto por MacKinnon, Lockwood, Hoffman, West, e Sheets (2002). Esta estatística é reapresentada através da seguinte fórmula: $\mathrm{z}^{\prime}=\alpha * \beta / \sqrt{ }(\alpha 2 * \sigma \beta 2+\beta 2 * \sigma \alpha 2)$ A hipótese nula refere-se à inexistência de efeitos indiretos $\left(\mathrm{H} 0: \mathrm{z}^{\prime}=0\right)$, sendo o valor crítico, a um nível de significância de 0,05, de 0,97 (MacKinnon et al , 2002).
} 
multigrupos ${ }^{9}$, já que "a análise multigrupos tem como objetivo avaliar se a estrutura do modelo de medida e / ou do modelo estrutural é equivalente (invariante) em diferentes grupos ou populações com características diferentes" (Maroco, 2007: 275). Procurou-se assim estudar se existem diferenças significativas no modelo proposto quando se está perante um perfil de dever moral ou um perfil de obrigação por dívida.

Os resultados apontam para a variância da matriz gama e beta (Tabela 7), sendo a hipótese nula rejeitada. Verifica-se assim que, de fato, existem diferenças significativas nos dois grupos (não rejeição da H5).

Tabela 7

Teste das hipóteses H5

\begin{tabular}{|c|c|c|c|}
\hline Hipótese & & $\Delta \chi^{2}$ & Conclusão \\
\hline H5 & 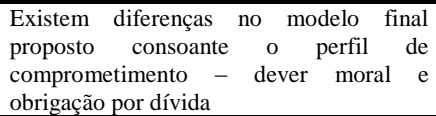 & $\begin{array}{c}\Delta \chi^{2}=4,74 \text { com } 7 \text { Graus de } \\
\text { Liberdade }\end{array}$ & $\begin{array}{l}\text { Não } \\
\text { Rejeitada }\end{array}$ \\
\hline
\end{tabular}

Depois de se verificar que, de fato, existem diferenças significativas consoante os perfis H5 (Tabela 7), importa então analisar a influência de cada perfil no modelo em estudo (H6). O quadro abaixo sistematiza os resultados obtidos pelo que, através desta informação será possível descortinar cada uma das hipóteses formuladas (Tabela 8).

A componente afetiva não altera a intensidade da sua relação de antecedência com a voz, de um perfil para outro (rejeição da H6.1). No entanto, verifica-se uma alteração da reação desta componente em relação à satisfação (H6.2), já que no perfil obrigação por dívida o valor da relação é negativo. Este dado é inconsistente com a literatura existente, já que estabelece esta relação como sendo positiva. Apesar da hipótese 6.2 não ser rejeitada, pois no perfil dever moral a intensidade é maior, este resultado não é totalmente convincente, surgindo então espaço para

\footnotetext{
9 Inicialmente foram criadas novas variáveis referentes aos dois perfis do comprometimento. Criou-se então um primeiro grupo (dever moral), que correspondia aos participantes com um valor na componente afetiva e normativa superior à média $(\mathrm{N}=117)$. O segundo grupo (obrigação por dívida), é constituído pelos participantes, com um valor da componente calculativa e normativa superior à média $(\mathrm{N}=107)$. Após esta fase, o modelo foi analisado com restrições, seguida da análise sem restrições. Finalmente, testou-se a hipótese nula da invariância das matrizes gama e beta nos dois grupos, através do valores de $\chi^{2}$. Verificou-se que a diferença do $\chi^{2}$ é de 4,74 para 7 graus de liberdade, sendo essa diferença significativa, pelo que, não se rejeita a hipótese da existência de diferenças entre os dois perfis (H5) (Tabela 7). Este teste tem como base a diferença dos valores de $\chi^{2}$ na solução com e sem restrições.
} 
estudos futuros sobre esta temática, no sentido da sua confirmação e também da sua explicação.

Tabela 8

Teste das hipóteses H6

\begin{tabular}{|c|c|c|c|c|}
\hline Hipótese & & $\begin{array}{l}\text { Perfil Dever } \\
\text { Moral }\end{array}$ & $\begin{array}{l}\text { Perfil } \\
\text { Obrigação } \\
\text { por Dívida }\end{array}$ & Conclusão \\
\hline 6.1 & $\begin{array}{l}\text { O CAf irá ser mais determinante da } \\
\mathrm{V} \text { no perfil dever moral face ao } \\
\text { perfil obrigação por dívida. }\end{array}$ & 0,77 & 0,71 & Rejeitada \\
\hline 6.2 & $\begin{array}{l}\text { O CAf irá ser mais determinante da } \\
\text { Sat no perfil dever moral do que no } \\
\text { perfil obrigação por dívida. }\end{array}$ & 0,26 & $-0,18$ & Não Rejeitada \\
\hline 6.3 & $\begin{array}{l}\text { A influência do CN sobre a V não se } \\
\text { altera em qualquer dos perfis. }\end{array}$ & $-0,41$ & $-0,29$ & Rejeitada \\
\hline 6.4 & $\begin{array}{l}\text { A influência do CN sobre a Sat não } \\
\text { se altera em qualquer dos perfis. }\end{array}$ & 0,03 & 0,30 & Rejeitada \\
\hline 6.5 & $\begin{array}{l}\text { O CC irá ser mais determinante da } \\
\mathrm{V} \text { no perfil obrigação por dívida } \\
\text { face ao perfil dever moral. }\end{array}$ & $-0,35$ & $-0,24$ & Rejeitada \\
\hline 6.6 & $\begin{array}{l}\text { O CC irá ser mais determinante da } \\
\text { Sat no perfil obrigação por dívida } \\
\text { que no perfil dever moral. }\end{array}$ & 0,32 & 0,43 & Não Rejeitada \\
\hline 6.7 & $\begin{array}{l}\text { A relação entre a Sat e a V não se } \\
\text { altera consoante os perfis }\end{array}$ & $-0,47$ & $-0,22$ & Rejeitada \\
\hline
\end{tabular}

Adicionalmente, estes resultados são esperados no perfil dever moral, mas são paradoxais no perfil obrigação por dívida, na medida em que este perfil não contempla esta componente afetiva. Coloca-se assim a questão da importância que a componente afetiva assume, aspeto que tem vindo a ser abordado por diferentes autores, entre os quais Meyer e Parfyonova (2010).

No modelo proposto a componente calculativa também foi identificada como um fator determinante, negativo, da voz. No caso da relação desta componente com a voz, verifica-se que o comprometimento calculativo assume mais influência no perfil dever moral que no perfil obrigação por dívida, rejeitando-se assim a hipótese H6.5. Este resultado também é paradoxal visto esta componente não ser parte integrante do perfil dever moral. No entanto, quando se analisa a relação da componente calculativa com a satisfação, verifica-se que é mais determinante no perfil obrigação por dívida (H6.6), não rejeitando assim a hipótese visto este perfil ser composto por esta componente.

No caso do comprometimento normativo, por ser elemento compósito dos dois perfis, as hipóteses formuladas (H6.3 e H6.4) postulavam que esta componente não era determinante de nenhuma relação, em nenhum dos perfis. Ambas as hipóteses foram rejeitadas verificando-se então que a componente normativa é mais determinante na relação com a voz, no 
perfil dever moral (H6.3) e é mais determinante na relação com a satisfação, no perfil obrigação por dívida (H6.4).

No caso a relação entre a satisfação e a voz (H6.7) a hipótese é rejeitada na medida em que se verifica que o perfil dever moral é mais determinante dessa relação, tornando-a negativa. No caso do perfil obrigação por dívida, esta relação também se torna negativa, porém, perde significância.

\section{CONCLUSÕES}

Ao nível das principais conclusões, verifica-se que esta amostra apresenta baixos níveis de comprometimento, de satisfação e também de exercício da voz. De fato, neste contexto não é possível compreender o tipo de voz existente, ou seja, se se está perante uma voz ativa e construtiva, como a literatura refere ou, tendo em conta os resultados do nível de comprometimento e de satisfação, se esta voz se caracteriza mais por uma componente defensiva ou até mesmo destrutiva. Este fator pode ser considerado como uma limitação do estudo sendo então proposto a realização de estudos futuros que se foquem na análise pormenorizada desta estratégia e / ou na relação entre as diferentes estratégias no modelo proposto.

Ao nível do comprometimento, a componente afetiva, ou seja, a relação de cariz emocional que se estabelece entre o colaborador e a organização, apresenta o resultado médio mais favorável, resultado esse que vem na mesma linha dos resultados onde esta componente se assume como fator determinante, tanto da satisfação como da voz.

De notar que os dois perfis do comprometimento influenciam, de fato, o modelo proposto, sendo que esta influência é mais visível na relação que se estabelece entre o comprometimento normativo (sentido de dever e responsabilidade) e a voz, e entre a satisfação e a voz, na medida em que a sua introdução produz uma relação negativa entre os constructos.

O comprometimento calculativo mantém-se relativamente estável com a introdução dos perfis o que significa que, independentemente do grupo se caracterizar pela realização de ações que são moralmente corretas ou que visam minimizar custos associados à sua não realização, os sujeitos tendem a associá-lo positivamente com a satisfação e negativamente com o exercício da voz.

O comprometimento normativo, apesar de ser o elemento comum aos dois perfis, não assume, nesta amostra, um papel determinante para compreender a satisfação dos colaboradores e a sua participação.

Assim, tendo em conta a relevância desta temática para a compreensão dos fenómenos sociais em contexto organizacional, sugere- 
se a continuação do estudo do comprometimento organizacional, segundo a perspetiva dos perfis de comprometimento e a sua influência noutros fenómenos organizacionais.

Ressalve-se, igualmente, uma condicionante deste trabalho, decorrente da homogeneidade da amostra obtida, caracterizada pela sua componente industrial. Neste sentido, propõe-se a realização de um estudo com uma amostra de maior dimensão e mais heterogénea ao nível do setor de atividade ou, por outro lado, proceder-se a um estudo comparativo, por setor.

Desta forma, a questão que se coloca com os resultados obtidos prende-se fundamentalmente com o papel da gestão dos afetos nas organizações. Tendo em consideração (1) a atual conjuntura, marcada pela imprevisibilidade e pela necessidade das organizações se tornarem sistemas abertos e sistémicos, e (2) as características peculiares da amostra obtida, maioritariamente industrial, propõe-se um desafio para a Gestão de Recursos Humanos que passaria por uma gestão focada nos afetos dado que são eles os fatores determinantes para a satisfação com o trabalho e, consequentemente, para o exercício de uma voz participativa.

\section{REFERÊNCIAS}

Baron, R. M., e Kenny, D. A. (1986). The moderator-mediator variable distinction in social psychology research: conceptual and statistical considerations. Journal of Personality and Social Psychology, 51(6), 1173-1182

Drucker, P. (1996). A Gestão numa Época de Grande Mudança. Lisboa: Difusão Cultural

Farrell, D. (1983). Exit, voice, loyalty, and neglect as responses to job satisfaction: A multidimensional scaling study. Academy of Management Journal, 26 (4), 596- 607.

Farrell, D., e Rusbult, C. E. (1981). Exchange variables as predictors of job satisfaction, job commitment and turnover: The impact of rewards, cost, alternatives and investiments. Organizational Behavior and Human Performance, 27, 78-95.

Farrell, D., e Rusbult, C. E. (1992). Exploring the exit, voice loyalty, and neglect typology: The influence of job satisfaction, quality of alternatives, and investment size. Employee Responsibilities and Rights Journal, 5 (3), 201-218.

Gellaty, I. R., Meer, J.P., e Luchak, A. A. (2006). Combined effects of the three commitment components on focal and discretionary behaviors: A test of Meyer an Herscovitch's propositions. Journal of Vocational Behavior, 69, 331-345 
Hackman, J. R. e Oldham, G. R. (1975). Development of the job diagnostic survey. Journal of Applied Psychology, 60, 159-170

Hackman, J. R. e Oldham, G. R. (1980). Work Redesign. Reading, Massachusetts, US: Addison-Wesley

Hair, J. F., Black, B., Babin, B. J., Anderson, R. E. e Tatham, R. L. (2006). Multivariate data analysis (6th ed.). Englewood Cliffs, USA: Prentice Hall

Hirschman, A. O. (1970). Exit, Voice, and Loyalty: Response to Decline in Firms, Organizations and States. Cambridge, Massachusetts, U.S.A.: Harvard University Pr Hollenbeck, J. R., e Klein, H. J. (1987). Goal commitment and the goal-setting process: Problems, prospects, and proposals for future research. Journal of Applied Psychology, 72 (2), 212-220.

MacKinnon, D. P., Fairchild, A. J., e Fritz, M. S. (2007). Mediation analysis. Annual Review Psychology, 58, 593-614

MacKinnon, D. P., Lockwood, C. M., Hoffman, J.M., West, S. G. e Sheets, V. (2002) A comparison of methods to test mediation and other intervening variable effects. Psychology Methods, 7(1), 83-104

Maroco, j. (2007). Análise Estatística - Com utilização do SPSS. Lisboa, Portugal: Editora Sílabo

Meyer, J. P. (2009). Commitment in a change world of work. In H. J. Klein, T. E. Becker, e J. P. Meyer (Eds.), Commitment in organizations: Accumulated wisdom and new directions (pp. 37-68). New York: Routledge Taylor \& Fracis Group.

Meyer, J. P., e Parfyonova, N. M.(2010). Normative commitment in the workplace: a theoretical analysis and re-conceptualization. Human Resources Management Review, 20, 283-294

Meyer, J. P., Allen, N. J., e Tololnytsky, R. (1998). Commitment in a changing world of work, Canadian Psychology

Meyer, J. P., e Allen, N. J. (1991). A three-component conceptualization of organizational commitment. Human Resources Management Review, 1 (1), 61-89.

Meyer, J. P., e Allen, N. J. (1997). Commitment in the workplace: Theory, Research, and Application. Thousand Oaks, California: Sage Publications.

Meyer, J. P., e Herscovitch, L. (2001). Commitment in the workplace: Toward a general model. Human Resource Management Review, 11, 299-326.

Meyer, J. P., Irving, P. G., e Allen, N. J. (1998). Examination of the combined effects of work values and early work experiences on organizational commitment. Journal of Organizational Behavior, 19, $29-52$. 
Nascimento, J. L., Lopes, A., e Salgueiro, M. F. (2008). Estudo sobre a validação de "Modelo de Comprometimento Organizacional" de Meyer e Allen para o contexto português. Comportamento Organizacional e Gestão, 14 (1), 115-133.

Nascimento, J.L. (2010) Influência do Comprometimento Organizacional nas Estratégias Comportamentais, mediadas pelo Comprometimentos com os Objectivos e pela Satisfação Global com $o$ Trabalho. Tese de Doutoramento, Especialidade em organização e Desenvolvimento de Recursos Humanos, INDEG-ISCTE

Rusbult, C. E., e Farrell, D. (1983). A longitudinal test of investment model: The impact on job satisfaction, job commitment, and turnoves of variations in rewards, costs, alternatives, and investments. Journal of Applied Psychology, 68 (3), 429-438.

Salgueiro, M. F.(2008). Modelos de Equações Estruturais: Aplicações com LISREL. Documento de trabalho não publicado, ISCTE, Lisboa, Portugal

Vanderberg, R. J., e Lance, C. E. (1992). Examing the casual order of job satisfaction and organizational commitment. Journal of Management, 18(1), 153-167

Wasti, S. A. (2005). Commitment profiles: combinations of organizational commitment forms and job outcomes. Journal of Vocational Behavior, 67, 290-307

Weick, K. E. (1995). Sensemaking in Organizations. Thousand Oaks, California, U.S.A.: SAGE Publications 